\section{Community Pharmacy Versus Mail Order: An Uneven Comparison}

The article "A Retrospective Database Study Comparing Diabetes-Related Medication Adherence and Health Outcomes for Mail-Order Versus Community Pharmacy" by Schwab et al. in the March 2019 issue of JMCP serves as an important reminder of the potential pitfalls of measuring medication adherence with prescription claims data. ${ }^{1}$ In this article, the authors compare oral diabetes medication adherence among patients filling $80 \%$ or more of their medications at community pharmacies to a matched cohort of patients filling medications through Humana's mail-order program. Although the authors propensity-match cohorts so that they are similar in a number of important characteristics, they fail to account for a significant factor that has been proven to influence medication adherence: 90-day prescription enrollment.

The failure to account for this factor biases the results toward showing a benefit with mail-order programs, given the way in which medication adherence is measured with proportion of days covered (PDC). ${ }^{2}$ Gaps between an actual fill date and an expected fill date based on days supply from a previous fill are counted as "uncovered" days in PDC measurement. Mathematically, the greater the number of gaps, the greater the opportunity to observe uncovered days and the lower the estimate of adherence. Over a 12-month period, the number of potential gaps is 3 with 90-day fills, compared with 11 with 30-day fills (see Figure).

It is important to remember that claims-based measures of adherence do not measure medication consumption but instead measure patterns of fills. Programs using 90-day fills have been reported to result in greater medication disposal. ${ }^{3}$ There are also numerous anecdotes suggesting that the scale of waste associated with medication disposal in mail-order programs is not insignificant. ${ }^{4}$ The finding that mail-order patients had no improvement in hemoglobin Alc $<7 \%$ at any point, as well as minimal improvement at 12 months and no improvement at 48 months in Alc $<8 \%$, is surprising given the magnitude of adherence reported by the authors. This finding provides further indication that the adherence improvement was potentially an artifact of measurement and does not capture actual improvements in diabetes medication consumption.

Finally, the assumption that mail-order filling results in lower inpatient hospitalization and emergency department (ED) usage is not supported by the study design selected by the authors. Given the lack of a preperiod before mail-order enrollment for comparison, the study relies on a posttest comparison of health service use. As such, the rates of hospitalization and ED use reported in this study likely reflect residual confounding between groups not controlled for in the propensity-matching approach.

To attract patients into mail-order programs, health plans such as Humana, which own mail-order pharmacies and have a profit incentive to keeping patients in-house, offer copayment reductions in mail-order programs. There is considerable literature suggesting improvements in adherence associated with reduced copayments, but this analysis was unable to parse out the effect this may have had on the results..$^{5}$ If the motive of plans was to improve patient adherence, differential copay and 90-day supply practices would be adopted regardless of which pharmacy a patient selects and include mail and community pharmacies alike.

\section{Joel F. Farley, PhD}

Professor, Department of Pharmaceutical Care \& Health Systems University of Minnesota College of Pharmacy

farl0032@umn.edu

\section{Benjamin Y. Urick, PharmD, PhD}

Research Assistant Professor

University of North Carolina Eshelman School of Pharmacy

\section{Stephen W. Schondelmeyer, PharmD, PhD}

Professor and Chair, Department of Pharmaceutical Care

\& Health Systems

University of Minnesota College of Pharmacy

FIGURE Differences in Gap Availability Between 30-Day and 90-Day Prescription Fills

\begin{tabular}{|c|c|c|c|c|c|c|c|c|c|c|}
\hline January & February & March & April & May & June & July & August & September & October & November December \\
\hline 1 & \multicolumn{2}{|c|}{ 90-Day Fill 1} & \multicolumn{3}{|c|}{ 90-Day Fill 2} & \multicolumn{4}{|c|}{ 90-Day Fill 3} & 90-Day Fill 4 \\
\hline
\end{tabular}

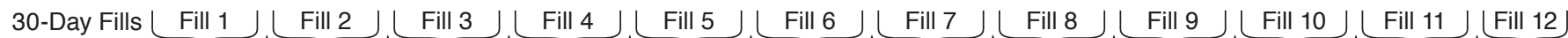

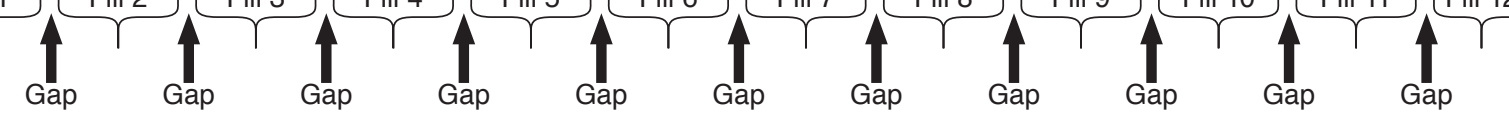




\section{DISCLOSURES}

No outside funding supported the writing of this letter. Farley has received funding from the National Community Pharmacy Association for previous research. Schondelmeyer advises the University of Minnesota Health Benefit plan on its prescription drug coverage. Urick has received a grant from Cardinal Health for previous research.

\section{REFERENCES}

1. Schwab P, Racsa P, Rascati K, Mourer M, Meah Y, Worley K. A retrospective database study comparing diabetes-related medication adherence and health outcomes for mail-order versus community pharmacy. J Manag Care Spec Pharm. 2019;25(3):332-40. Available at: https://www.jmcp.org/ doi/10.18553/jmcp.2019.25.3.332.

2. Nau DP. Proportion of days covered as a preferred method of measuring medication adherence. May 2011. Available at: http://ep.yimg.com/ty/cdn/ epill/pdcmpr.pdf. Accessed May 2, 2019

3. Taitel M, Fensterheim L, Kirkham H, Sekula R, Duncan I. Medication day's supply, adherence, wastage, and cost among chronic patients in Medicaid. Medicare Medicaid Res Rev. 2012;2(3). pii: mmrr.002.03.a04.

4. National Community Pharmacist Association. Mail order waste. Available at: https://www.ncpanet.org/pdf/leg/sepll/mail_order_waste.pdf. Accessed May 2, 2019.

5. Farley JF, Wansink D, Lindquist JH, Parker JC, Maciejewski ML. Medication adherence changes following value-based insurance design. Am J Manag Care. 2012;18(5):265-74.

\section{The Authors Respond}

The letter by Farley, Urick, and Schondelmeyer regarding the study "A Retrospective Database Study Comparing DiabetesRelated Medication Adherence and Health Outcomes for MailOrder Versus Community Pharmacy" provides a thoughtful, critical commentary for the study of mail-order and community pharmacy that necessitates a response. They note that there is greater opportunity for uncovered days in a proportion of days covered (PDC) measure with 30-day fills than is typical for a community pharmacy as compared with 90-day fills, which are the norm for mail-order pharmacies, and that the 90-day fills could appear to infer adherence when wastage is occurring. Wastage seems most likely to occur when early discontinuation follows large quantities for initial fills rather than with long-term use. Schwab et al., the study authors, ${ }^{1}$ observed PDC differences that sustained over multiple years, demonstrating refilling behavior that is inconsistent with excess wastage. The authors also addressed this concern by noting that the Medicare Advantage prescription drug plans studied require patients to initiate or authorize each refill. Greater adherence for mail order was not merely an artifact of pharmacy claims data.

The commenters stated that posttest comparative analyses of inpatient hospitalizations and emergency department visits were subjected to confounding due to the lack of preperiod measurements, while also suggesting that the propensity scorematching methods provided insufficient control. The authors contend that propensity score matching was an appropriate method for the study. ${ }^{2}$ The commenters either disagree with the application of propensity score matching altogether or they failed to notice that the propensity score in the study included preperiod health care utilization and preperiod cost measures.

The commenters may have confused the concepts of study treatment and bias when interpreting the study findings. ${ }^{3}$ The treatment for this study was the type of dispensing pharmacy. Pharmacies were differentiated based on greater use of 90-day supply fills and use of home delivery for mail-order pharmacies, which is expected to result in greater adherence. ${ }^{4}$ The expressed differences between mail-order and community pharmacies were not confounders that biased the analyses but were fundamental attributes of the treatment that served as the theoretical foundation for the hypothesis. The authors presented this theoretical basis in the opening of the article and reiterated it at the end.

The commenters noted that patients' out-of-pocket costs were not mentioned. Individual claim costs and patient out-ofpocket costs vary quite a bit based on health plan, drug coverage, low-income subsidy status, and coverage gap. Regardless of individual claim costs, it is reasonable to believe that patients' costs per month were lower for mail order due to fewer fills per month, but mail order drives additional drug expenditure through adherence. ${ }^{5,6}$ Nevertheless, if mail-order patients benefited from lower costs, then PDC and adherence may have been influenced positively. As with 90-day supplies, lower cost would be an attribute of mail-order pharmacy, not a biasing confounder.

The authors agree that if mail-order pharmacy and community pharmacy was not differentiated by 90 -day supply fills and delivery to the home, then the effects observed in this study probably would not exist, yet these differentiations were essential.

\section{Phil Schwab, PhD}

Research Consulting Lead

Humana Healthcare Research

pschwab@humana.com

\section{Patrick Racsa, MS}

Senior Research Scientist

Humana Healthcare Research

\section{Karen Rascati, RPh, PhD}

Professor

The University of Texas at Austin

Marc Mourer, MBA

Channel Development Professional Lead

Humana Healthcare Services 